\title{
Predicting preferred prey of Sumatran tigers Panthera tigris sumatrae via spatio-temporal overlap
}

\author{
Maximilian L. Allen, Marsya C. Sibarani and Mina Krofel
}

\begin{abstract}
Encounter rates of carnivores with prey are dependent on spatial and temporal overlap, and are often highest with their preferred prey. The Critically Endangered Sumatran tiger Panthera tigris sumatrae is dependent on prey populations, but little is known about its prey preferences. We collected camera-trap data for 7 years (2010-2016) in Bukit Barisan Selatan National Park, Sumatra, to investigate spatial and temporal overlap of tigers with potential prey species. We also developed a novel method to predict predator-prey encounter rates and potential prey preferences from camera-trap data. We documented at least 10 individual tigers, with an overall detection rate of 0.24 detections $/ 100$ trap nights. Tigers exhibited a diurnal activity pattern and had highest temporal overlap with wild boar Sus scrofa and pig-tailed macaques Macaca nemestrina, but highest spatial overlap with wild boar and sambar deer Rusa unicolor. We created a spatial and temporal composite score and three additional composite scores with adjustments for the spatial overlap and preferred prey mass. Wild boars ranked highest for all composite scores, followed by sambar deer, and both are known as preferred tiger prey in other areas. Spatial and temporal overlaps are often considered as separate indices, but a composite score may facilitate better predictions of encounter rates and potential prey preferences. Our findings suggest that prey management efforts in this area should focus on wild boar and sambar deer, to ensure a robust prey base for this Critically Endangered tiger population.
\end{abstract}

Keywords Activity patterns, composite score, Panthera tigris, prey preference, spatial overlap, Sumatra, temporal overlap, tiger

Supplementary material for this article is available at doi.org/10.1017/So030605319000577

Maximilian L. Allen (Corresponding author, (1) orcid.org/0000-0001-8976889X) Illinois Natural History Survey, University of Illinois, 1816S. Oak Street, Champaign, Illinois 61820, USA. E-mail maxallen@illinois.edu

Marsya C. Sibarani Wildlife Conservation Society-Indonesia Program, Bogor, West Java, Indonesia

MiHa Krofel ([0 orcid.org/0000-0002-2010-5219) Department of Forestry, Biotechnical Faculty, University of Ljubljana, Ljubljana, Slovenia

Received 31 January 2019. Revision requested 16 April 2019.

Accepted 2 May 2019. First published online 9 March 2020.

\section{Introduction}

Tnterspecific interactions are important aspects of com1 munity ecology, affecting the functional ecology of ecosystems and dictating the ecological niches inhabited by species (Begon et al., 2006). Such interactions can be difficult to assess, however, particularly for cryptic species such as wild carnivores (Allen et al., 2016; Saggiomo et al., 2017). Carnivore-prey encounter rates are dependent on spatial and temporal overlap, and high encounter rates are often indicative of prey preference (Holling, 1959; Fortin et al., 2015). Data on spatio-temporal overlap of carnivores with potential prey species may thus facilitate inference of prey preferences and patterns of interspecific interactions, providing insights into ecosystem functions that can inform effective conservation. Camera trapping is a non-invasive method that is increasingly being used to monitor wildlife and provides data on species richness, behaviour, and spatiotemporal activity (Swanson et al., 2015; Rich et al., 2016; Allen et al., 2017).

The tiger Panthera tigris is categorized as Endangered throughout its range, with four subspecies probably extinct in the wild (Seidensticker, 2010; Goodrich et al., 2015). The Sumatran tiger Panthera tigris sumatrae is Critically Endangered (Linkie et al., 2008), as are many other species on the Indonesian island of Sumatra (O'Brien \& Kinnaird, 1996; Pusparini et al., 2018). Prey abundance can have strong effects on the abundance and population density of tigers (Karanth et al., 2004; Barber-Meyer et al., 2012), and tiger declines have been linked to declines of prey in Russia and India (Miquelle et al., 1999; Ramakrishnan et al., 1999). The prey preferences of tigers are unknown in many areas, but such knowledge is important to inform conservation planning and ensure sufficient prey is available in areas critical to tiger conservation. Information about the Sumatran tiger's diet is limited (e.g. O'Brien et al., 2003; Linkie \& Ridout, 2011), and data on spatial and temporal activity patterns and overlap between tigers and potential prey could improve our understanding of the subspecies' prey preferences.

Bukit Barisan Selatan National Park is one of the largest protected areas on the island of Sumatra, and is critical for the conservation of the Sumatran tiger and other species of conservation concern, including the Critically Endangered Sumatran rhinoceros Dicerorhinus sumatrensis and Sumatran elephant Elephas maximus sumatranus (O’Brien \& Kinnaird, 1996; Pusparini et al., 2018). The Park provides relatively abundant tiger habitat, but threat levels are moderate to high because of inadequate conservation 
measures (Sanderson et al., 2010). Given the Park's importance for tiger conservation, it is important to understand the species' ecology in this area. Previous studies of activity patterns of Sumatran tigers in the Park produced conflicting results; O'Brien et al. (2003) reported tigers had a diurnal activity pattern, whereas Pusparini et al. (2018) reported a crepuscular activity pattern with highest activity levels near dawn. The tigers' prey preferences and prey abundance in the area are also unknown.

To inform conservation efforts, we investigated tiger spatio-temporal overlap with potential prey species, using 7 years of camera-trap data from an area of the Park with little human activity. Our objectives were to (1) document the minimum number of individual tigers in the area, (2) determine the temporal and spatial overlap of tigers with six potential prey species, and (3) create a composite score from the indices of temporal and spatial overlap as a novel method to predict predator-prey encounter rates and determine potential prey preference. In our analyses we included all potential tiger prey species present in the study area, based on a review of tiger dietary studies (Hayward et al., 2012). In line with known prey preferences of tigers across their range, we expected sambar deer Rusa unicolor and wild boar Sus scrofa to have the highest composite spatio-temporal score.

\section{Study area}

Our study site is in Bukit Barisan Selatan National Park, in the South Barisan Range ecosystem on the Indonesian island of Sumatra (Fig. 1). The Park is the third largest protected area $\left(3,560 \mathrm{~km}^{2}\right)$ on Sumatra (O'Brien \& Kinnaird, 1996), spanning two provinces: Lampung and Bengkulu. Topography ranges from coastal plains and lowland rainforest at sea level in the southern peninsula of the Park to mountains up to $1,964 \mathrm{~m}$ in the central and northern parts (Pusparini et al., 2018). The Park contains montane, lowland tropical, coastal and mangrove forests. Annual rainfall is $3,000-4,000 \mathrm{~mm}$, most of which falls in the monsoon season (November-May), and annual temperatures are $22-35^{\circ} \mathrm{C}$ (O'Brien et al., 2003). The Park contains a high diversity of wildlife, with tigers and 76 other species listed in the CITES Appendices and categorized as Endangered or Critically Endangered on the IUCN Red List.

\section{Methods}

\section{Camera trapping}

We set camera traps in the Park as part of the Tropical Ecology and Assessment Monitoring Network, which collects long-term biodiversity data in tropical environments globally to guide conservation actions. Our goal was to monitor the terrestrial vertebrate community, and we

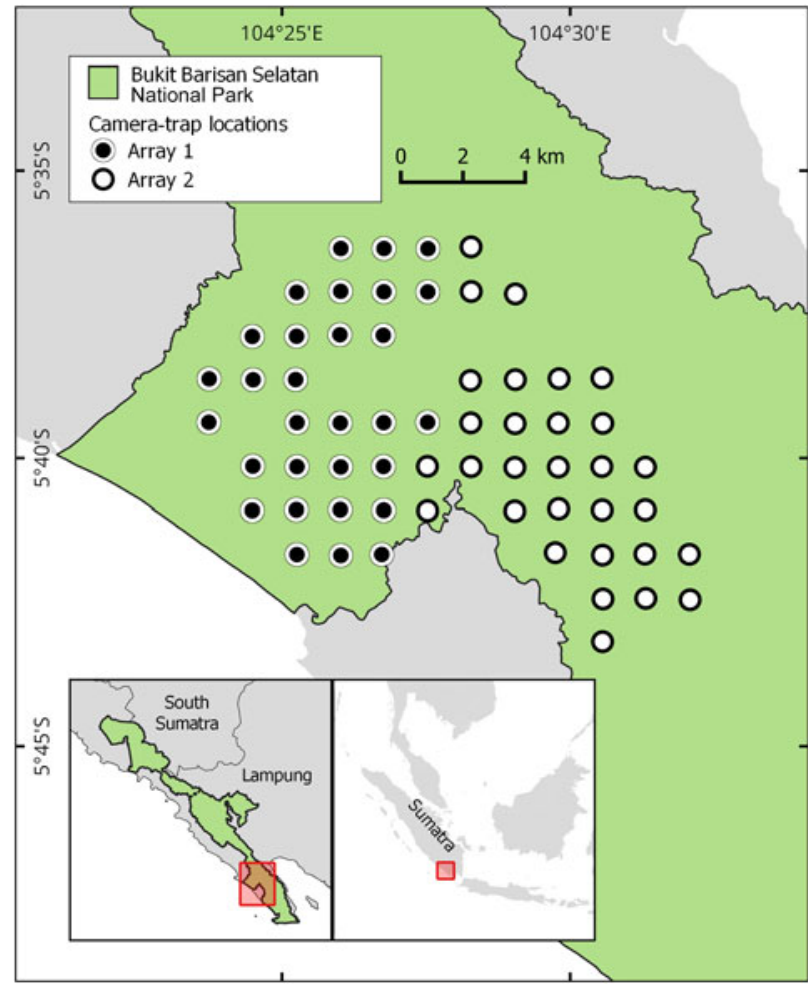

FIG. 1 The study site with camera-trap locations of both arrays within Bukit Barisan Selatan National Park on the island of Sumatra, Indonesia.

designed our survey to monitor multiple species effectively (Rich et al., 2019). We set two arrays of 30 camera traps, using the Network's protocols (TEAM Network, 2011), in sites chosen for accessibility for long-term repeated surveys, all in lowland forests at 16-320 m altitude. We placed camera traps in each array at a density of 1 per $2 \mathrm{~km}^{2}$ (Fig. 1), and the arrays covered a total of $128.43 \mathrm{~km}^{2}$. We deployed the camera-trap arrays in the dry season (April-July) of each year during 2010-2016, with array 1 in operation during April-May and array 2 during June-July, with the aim to complete at least 30 sampling days for each camera trap. We positioned camera traps near animal trails and/or places used regularly by wildlife, to maximize detections. We placed camera traps $30-50 \mathrm{~cm}$ off the ground, with no refractory period between images.

\section{Statistical analyses}

To avoid pseudo-replication, we considered consecutive photo captures of the same species as independent events only if they occurred after an interval of $>30 \mathrm{~min}$ (Rovero \& Zimmermann, 2016). We calculated the number of independent captures for each species, but combined both mouse deer species (greater mouse deer Tragulus napu and lesser mouse deer Tragulus kanchil) in one category because they share similar characteristics as potential 
tiger prey and it was difficult to distinguish between them on camera-trap images (O'Brien et al., 2003).

We used a relative abundance index as a proxy for tiger abundance, because this is a more accurate proxy for abundance than occupancy values (Parsons et al., 2017). We calculated the index as:

$$
\text { relative }=(\text { detection events/trap nights }) \times 100
$$

for each camera trap, to determine detection events per 100 trap nights (e.g. Allen et al., 2018), and averaged the values from all camera traps to determine an overall mean for the study area. We used the stripe patterns of individual tigers to identify the minimum number of individuals, separately for photographs of the right and left flanks.

We used kernel density estimation to determine activity patterns and quantify overlap among species (Ridout \& Linkie, 2009). We reviewed potential prey species for tigers (Hayward et al., 2012) and analysed those in our study area with $>75$ detection events, which included the greater and lesser mouse deer $(\mathrm{n}=340)$, Malay tapir Tapirus indicus $(\mathrm{n}=85)$, pig-tailed macaque Macaca nemestrina $(\mathrm{n}=433)$, red muntjac Muntiacus muntjac $(\mathrm{n}=711)$, sambar deer $(n=102)$, and wild boar $(n=302)$. We first converted the time of each event into a radians measurement for analysis. We then used the overlap package (Meredith \& Ridout, 2017) in $R$ 3.3.1 (R Core Team, 2016) to fit the data to a circular kernel density, and estimated the activity level at each time period from the distribution of the kernel density using a $\Delta_{1}$ overlap value based on our sample sizes. We used the overlapEst function to estimate the degree of overlap in activity patterns between tigers and the potential prey species. We calculated confidence intervals (CI) by bootstrapping 10,000 estimates of activity for each species, and then using the bootEst and bootCI functions to estimate the $95 \%$ CI for the overlap between tigers and each potential prey species.

To determine spatial overlap with potential prey species we used the methods of Ngoprasert et al. (2012). We first calculated the relative abundance index for each prey species, as for tigers, and then scaled the index for each prey species at each camera-trap site to continuous probability values of o-1 (Ngoprasert et al., 2012). We then created a logistic regression for each prey species using data from each camera-trap location. In the logistic regression we used tiger presence as the dependent variable and prey probability values as the independent variable. We then compared spatial overlap of prey species using the area under the curve (AUC) of receiver operating characteristic plots (Fielding \& Bell, 1997), and quantified the spatial overlap of tigers with individual prey species as the AUC values, which range from 0.5 (random) to 1.0 (perfect fit).

To determine which prey species may be preferred we plotted the spatial and temporal overlap of tigers with each potential prey species. The upper right quadrant of the plot (high spatial and temporal overlap) indicates the most encountered and potentially most preferred prey species, whereas the upper left (high temporal but low spatial overlap) and lower right (low temporal but high spatial overlap) quadrants would indicate potential alternative prey that were encountered opportunistically in space or time. The lower left quadrant (low spatial and temporal overlap) would indicate species rarely encountered and probably not preferred.

Finally, we calculated the mean of the spatial and temporal overlap values for each prey species to create a spatial and temporal composite score (Song et al., 2013). This allowed us to rank the potential prey species, with higher scores indicating higher encounter rate and potentially higher preference.

We expected that this simple composite score could be improved by giving additional weight to some variables or including other variables in the score. We therefore calculated three additional composite scores to determine how different weighting of overlap scores or the inclusion of additional variables affect the preference rankings of potential prey.

Firstly, we assigned more weight to the spatial overlap value, because spatial overlap with prey is an important aspect of niche selection and resource partitioning for carnivores (Schoener, 1974; du Preez et al., 2017) and may better reflect prey species being sought out, compared to temporal overlap. We calculated the spatial adjusted composite score as:

$$
\begin{aligned}
& \text { spatial adjusted } \\
& \text { composite score }
\end{aligned}=\begin{aligned}
& (\text { spatial overlap } \times 0.6)+ \\
& (\text { temporal overlap } \times 0.4)
\end{aligned}
$$

Secondly, we considered a composite score that also included prey mass, with a higher mass adjustment value (spatial and temporal composite score $\times 1.1)$ for prey within the preferred size range of tigers (60-250 kg; Hayward et al., 2012) and a lower value (spatial and temporal composite score $\times 0.9$ ) for potential prey outside this range. We obtained prey mass values from Nowak (1999) and used 75\% of the mean weight of adult females to account for young animals being eaten (Hayward et al., 2012). We then calculated the mass adjusted composite score as:

$$
\underset{\text { composite score }}{\text { mass adjusted }}=\begin{gathered}
(\text { spatial overlap } \times \text { temporal overlap }) \times \\
\text { mass adjustment }
\end{gathered}
$$

Thirdly, we calculated a spatial and mass adjusted composite score as:

$$
\begin{gathered}
\text { spatial and mass } \\
\text { adjusted composite score }
\end{gathered}=\begin{gathered}
((\text { spatial overlap } \times 0.6)+ \\
\text { mass adjustment }
\end{gathered}
$$

We then ranked potential prey species based on each composite score, with higher scores indicating higher encounter rate and potentially higher preference. 
TABLE 1 The indices of potential prey species of tigers Panthera tigris sumatrae in Bukit Barisan Selatan National Park, Sumatra, including relative abundance (detection events/10o trap nights), temporal overlap, spatial overlap, and composite scores. Higher composite scores indicate greater encounter rates and potential prey preference. Species are listed in order of their spatial and temporal composite score.

\begin{tabular}{|c|c|c|c|c|c|c|c|}
\hline \multirow[b]{2}{*}{ Species } & \multirow[b]{2}{*}{$\begin{array}{l}\text { Relative } \\
\text { abundance }\end{array}$} & \multirow[b]{2}{*}{$\begin{array}{l}\text { Temporal } \\
\text { overlap }\end{array}$} & \multirow[b]{2}{*}{$\begin{array}{l}\text { Spatial } \\
\text { overlap }\end{array}$} & \multicolumn{4}{|c|}{ Composite scores } \\
\hline & & & & $\begin{array}{l}\text { Spatial \& } \\
\text { temporal }\end{array}$ & $\begin{array}{l}\text { Spatial } \\
\text { adjusted }\end{array}$ & $\begin{array}{l}\text { Prey mass } \\
\text { adjusted }\end{array}$ & $\begin{array}{l}\text { Spatial \& prey } \\
\text { mass adjusted }\end{array}$ \\
\hline Wild boar Sus scrofa & 3.15 & 0.80 & 0.71 & 0.76 & 0.77 & 0.83 & 0.84 \\
\hline Sambar Rusa unicolor & 1.02 & 0.70 & 0.66 & 0.68 & 0.67 & 0.75 & 0.74 \\
\hline $\begin{array}{l}\text { Pig-tailed macaque } \\
\text { Macaca nemestrina }\end{array}$ & 4.32 & 0.76 & 0.60 & 0.68 & 0.66 & 0.61 & 0.60 \\
\hline $\begin{array}{l}\text { Red muntjac } \\
\quad \text { Muntiacus muntjac }\end{array}$ & 7.10 & 0.68 & 0.57 & 0.63 & 0.62 & 0.56 & 0.56 \\
\hline Mouse deer ${ }^{1}$ & 3.39 & 0.62 & 0.53 & 0.58 & 0.57 & 0.52 & 0.51 \\
\hline Tapir Tapirus indicus & 0.85 & 0.43 & 0.52 & 0.48 & 0.48 & 0.52 & 0.53 \\
\hline
\end{tabular}

${ }^{1}$ Greater mouse deer Tragulus napu and lesser mouse deer Tragulus kanchil.

\section{Results}

We had 60 camera traps operating during 2010-2016 for a total of 10,018 trap nights. We obtained 45,444 photographs of 48 species, including 37 mammals. We documented all six potential tiger prey species in all 7 years of the study. We captured photographs of people 10 times in 4 study years $(2012=1,2013=2,2015=4,2016=3)$, and one domestic dog in 2016.

We recorded a total of 27 tiger captures $(2010=6,2011=4$, $2012=5,2013=4,2014=5,2015=3,2016=0$ ), with an overall relative abundance of $0.24 \pm \mathrm{SE} 0.08$ detections/100 trap nights per camera trap. We identified at least 10 individual tigers in left flank photographs and eight individuals in right flank photographs (Supplementary Material 1).

We documented 1,987 captures of potential prey species, with red muntjacs being recorded most frequently, followed by pig-tailed macaques and mouse deer (Table 1). Tigers exhibited a diurnal activity pattern (Fig. 2) and had the highest temporal overlap with wild boar, followed by pig-tailed macaques and sambar (Fig. 2, Table 1). The highest spatial overlap was also with wild boar, followed by sambar and pig-tailed macaques (Table 1 ).

When plotting the values indicating spatial and temporal overlap of tigers with potential prey species, wild boar and sambar deer fell in the upper right quadrant, suggesting they are potentially preferred prey. Tapirs were in the lower left quadrant, indicating they were probably not preferred, and the other prey species were in the upper left (high temporal but low spatial overlap), indicating potential alternative prey (Fig. 3).

Tigers had the greatest spatio-temporal overlap with wild boar, with a spatial and temporal composite score of 0.76 , which is $11 \%$ higher than the species with the second highest scores (sambar and pig-tailed macaques, both o.68; Table 1).

The additional composite scores produced a similar ranking to the spatial and temporal composite score. Wild boar ranked highest for the spatial adjusted composite score, the prey mass adjusted score and the spatial and prey mass adjusted score, with scores $11-13 \%$ higher than the next species (Table 1). As for the spatial and temporal composite score, sambar and pig-tailed macaques also ranked second and third, respectively, for these additional composite scores. The spatial adjusted composite scores for sambar and pig-tailed macaque were similar (sambar scored $1.5 \%$ higher than pig-tailed macaque), but the difference was greater for the prey mass adjusted score and the spatial and prey mass adjusted score (sambar scored $23 \%$ higher for both of these scores).

\section{Discussion}

The tiger is an important flagship species for conservation, but remains threatened throughout its range (Seidensticker, 2010; Walston et al., 2010; Sibarani et al., 2019). Sumatran tigers are categorized as Critically Endangered (Linkie et al., 2008) and tiger populations in Bukit Barisan Selatan National Park and other areas are threatened by encroachment and habitat destruction (O'Brien \& Kinnaird, 1996; Pusparini et al., 2018), and by poaching of tigers and/or their prey (Linkie et al., 2003, 2008). Effective conservation is dependent on collaboration between countries, government agencies, local communities, and scientific organizations. The Tropical Ecology and Assessment Monitoring Network is focused on open sharing of scientific data and can be used as a model for data sharing amongst scientists and other stakeholders for conservation.

We found tigers exhibited diurnal activity patterns, and we created a composite score of spatial and temporal overlap with potential prey species to provide insights into tiger prey preferences, which can inform conservation (e.g. Karanth et al., 2004; Barber-Meyer et al., 2012). Previous studies in the study area suggested tigers have a diurnal activity pattern (O'Brien et al., 2003), or a crepuscular pattern with highest activity near dawn (Pusparini et al., 2018). The 

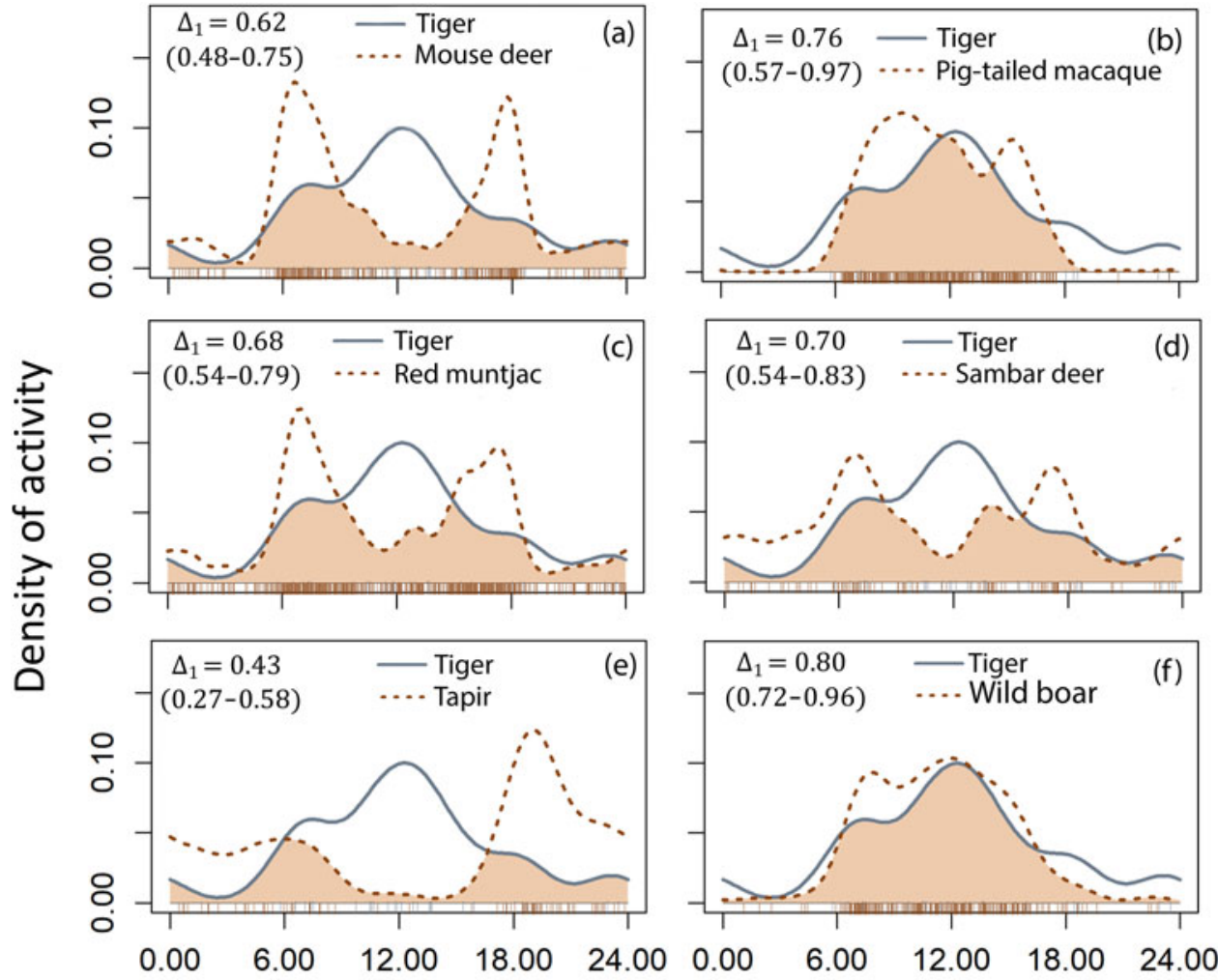

Time of day
FIg. 2 The temporal activity (including 95\% confidence intervals) and overlap of the kernel activity density of tigers and potential prey species: (a) mouse deer (including greater mouse deer Tragulus napu and lesser mouse deer Tragulus kanchil), (b) pigtailed macaque Macaca nemestrina, (c) red muntjac Muntiacus muntjac, (d) sambar deer Rusa unicolor, (e) tapir Tapirus indicus, (f) wild boar Sus scrofa. Tiger activity is represented as solid lines and prey activity as dotted lines, with their temporal overlap shown as the shaded area.

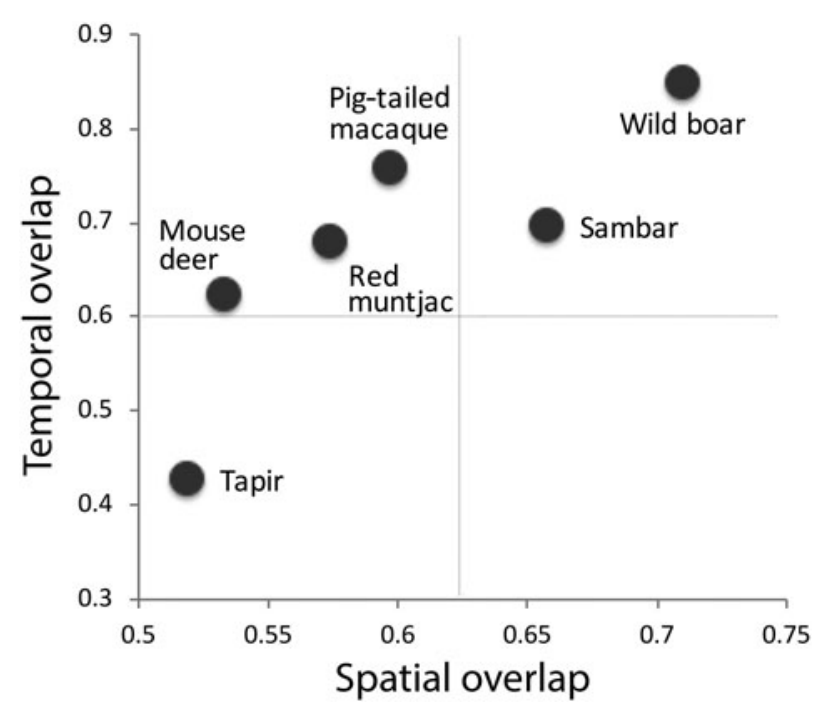

FIG. 3 The spatial (area under curve; AUC) and temporal (kernel density) overlap of tigers with potential prey species plotted together (with axes scaled to the reported values for ease of comparison).

sample size of tiger captures in our study was lower than in both previous studies, but our findings appear to confirm the diurnal activity pattern observed by O'Brien et al. (2003). Reasons for the observed differences could be different sampling techniques, variation in individual tiger behaviour, or varying degrees of interactions with humans or other species in different parts of the Park. For example, Pusparini et al. (2018) reported high rates of illegal human activity (photographic captures of humans with guns) and relative tiger abundances (relative abundance index $=0.99$ ) that were an order of magnitude higher than in our study (relative abundance index $=0.24$ ). This may have caused tigers to change their activity patterns to avoid threats posed by humans (e.g. Clinchy et al., 2016). Further research is required to ascertain reasons for these conflicting results from the same Park and subpopulation.

A high degree of spatio-temporal overlap does not necessarily indicate prey preference but it suggests potential for high encounter rates between carnivores and their prey, which is a key component of prey preference (Holling, 1959; Fortin et al., 2015). Temporal overlap has been posited as a way of determining prey preferences (Linkie \& Ridout, 2011), but probably provides an incomplete picture if spatial overlap is not included (e.g. O'Brien et al., 2003). Other factors to be considered include prey body size and potential avoidance strategies by prey species. We created four composite index scores that included both temporal and spatial overlap. Each composite score appears to accurately rank prey preference of tigers in Bukit Barisan Selatan National Park, with wild boar and sambar deer being the most preferred, as predicted based on the findings of Hayward et al. (2012). The spatial and temporal 
composite score was effective, but the scores including preferred prey mass better separated sambar and pig-tailed macaques as potential prey species for tigers. We used small (10\%) adjustments to create the adjusted composite scores, and future studies in areas with known prey preferences could conduct sensitivity analyses to determine ideal weighting adjustments for spatial and temporal composite scores to determine prey preference.

The different composite scores indicated mostly the same ranking amongst potential prey species, with the only exception being tapirs ranking slightly higher than mouse deer in the spatial and mass adjusted composite score. Wild boar ranked highest in all cases, followed by sambar deer, and these two species are frequently the preferred prey of tigers throughout their range (Seidensticker \& McDougal, 1993; Hayward et al., 2012; Basak et al., 2018). The greater overlap and composite scores for wild boar in this study site could be a result of wild boar having a relative abundance c. three times greater than sambar deer. Species with higher abundance are probably more widely distributed across the landscape, which could inflate their spatial overlap with predators and potentially overestimate prey preference. Red muntjac, pig-tailed macaque and mouse deer were indicated as potential alternative prey species with intermediate composite index scores and a position in the upper left quadrant on the spatial and temporal overlap plot (Fig. 3), which indicates high temporal but low spatial overlap with tigers. Tapirs had low spatial and temporal overlap with tigers, which corresponds to published data and suggests they may be non-preferred prey of tigers (Hayward et al., 2012). Based on these results we suggest that conservation efforts in the area should be focused on wild boar and sambar deer, to ensure a robust prey base for this tiger population. We found evidence of illegal snares set for sambar deer in the Park, suggesting conservation actions may be necessary.

Prey preference is usually assessed using the ratio of prey killed to prey available, and our study shows a potential alternative method to predict prey encounter rates and preference. Determining the number of prey of different species killed by tigers, or numbers of prey available, can be costly and time-intensive compared to using camera traps to collect relative abundance data. Our method of plotting spatial and temporal overlap between predator and prey species and creating composite index scores from camera-trap data could be useful for inferring the encounter rates of carnivores with prey and appears to have correctly ranked the prey preferences for Sumatran tigers. The inclusion of prey mass appeared to improve upon the spatial and temporal composite score, and including mass or other variables such as abundance or habitat preference may facilitate more effective inference in future studies, which could also fine-tune the values used in the adjusted composite scores. Further testing of a similar composite score for spatio-temporal overlap should be conducted in other systems with known prey preferences of carnivores (e.g. from dietary analyses) to further evaluate the accuracy of this method, assess general applicability of the method, and further interpret the observed relationships.

Acknowledgements All data used in this study were collected by the Tropical Ecology Assessment and Monitoring Network, a collaboration between Conservation International, the Missouri Botanical Garden, the Smithsonian Institution and the Wildlife Conservation Society. The work was partially funded by these institutions, the Gordon and Betty Moore Foundation, the Illinois Natural History Survey, the Slovenian Research Agency (P4-0059), and other donors. Monitoring activities were managed by the Wildlife Conservation Society in collaboration with the Bukit Barisan Selatan National Park and the Ministry of Environment and Forestry, Republic of Indonesia. We thank all field staff and forest rangers involved in camera-trap deployment, and W. Marthy for help in the field and coordination.

Author contributions Study concept: all authors; data collection: MCS; statistical analyses: MLA; writing: MLA; revisions: all authors.

\section{Conflicts of interest None.}

Ethical standards This research abided by the Oryx guidelines on ethical standards. The research was based on passive monitoring, and did not involve human subjects, experimentation with animals and/or collection of specimens.

\section{References}

Allen, M.L., Wilmers, C.C., Elbroch, L.M., Golla, J.M. \& Wittmer, H.U. (2016) The importance of motivation, weapons, and foul odors in driving encounter competition in carnivores. Ecology, 97, 1905-1912.

Allen, M.L., Gunther, M.S. \& Wilmers, C.C. (2017) The scent of your enemy is my friend? The acquisition of large carnivore scent by a smaller carnivore. Journal of Ethology, 35, 13-19.

Allen, M.L., Peterson, B. \& Krofel, M. (2018) No respect for apex carnivores: distribution and activity patterns of honey badgers in the Serengeti. Mammalian Biology, 89, 90-94.

Barber-Meyer, S.M., Jnawali, S.R., Karki, J.B., Khanal, P., Lohani, S., LonG, B. et al. (2012) Influence of prey depletion and human disturbance on tiger occupancy in Nepal. Journal of Zoology, 289, 10-18.

Basak, K., Mandal, D., Babu, S., Kaul, R., Ashraf, N.V.K., Singh, A. \& Mondal, K. (2018) Prey animals of tiger (Panthera tigris tigris) in Dudhwa landscape, Terai Region, North India. Proceedings of the Zoological Society, 71, 92-98.

Begon, M., Townsend, C.R. \& Harper, J.L. (2006) Ecology: From Individuals to Ecosystems. 4 th edition. Blackwell Publishing, Oxford, $\mathrm{UK}$.

Clinchy, M., Zanette, L.Y., Roberts, D., Suraci, J.P., Buesching, C.D., Newman, C. \& Macdonald, D.W. (2016) Fear of the human 'super predator' far exceeds the fear of large carnivores in a model mesocarnivore. Behavioral Ecology, 27, 1826-1832.

du Preez, B., Purdon, J., Trethowan, P., Macdonald, D.W. \& Loveridge, A.J. (2017) Dietary niche differentiation facilitates coexistence of two large carnivores. Journal of Zoology, 302, 149-156.

Fielding, A.H. \& Bell, J.F. (1997) A review of methods for the assessment of prediction errors in conservation presence/absence models. Environmental Conservation, 24, 38-49. 
Fortin, D., Buono, P.L., Schmitz, O.J., Courbin, N., Losier, C., St-Laurent, M.H. et al. (2015) A spatial theory for characterizing predator-multiprey interactions in heterogeneous landscapes. Proceedings of the Royal Society B: Biological Sciences, 282, 20150973.

Goodrich, J.M., Lyam, A., Miquelle, D.G., Wibisono, H.T., Kawanishi, K., Pattanavibool, A. et al. (2015) Panthera tigris. In The IUCN Red List of Threatened Species, e.T15955A50659951. dx.doi.org/10.2305/IUCN.UK.2015-2.RLTS.T15955A50659951.en [accessed 13 February 2020].

Hayward, M.W., Jedrzejewski, W. \& Jedrzewska, B. (2012) Prey preferences of the tiger Panthera tigris. Journal of Zoology, 286, 221-231.

Holling, C.S. (1959) The components of predation as revealed by a study of small mammal predation of the European pine sawfly. The Canadian Entomologist, 91, 293-320.

Karanth, K.U., Nichols, J.D., Kumar, N.S., Link, W.A. \& Hines, J.E. (2004) Tigers and their prey: predicting carnivore densities from prey abundance. Proceedings of the National Academy of Sciences of the United States of America, 101, 4854-4858.

Linkie, M. \& Ridout, M.S. (2011) Assessing tiger-prey interactions in Sumatran rainforests. Journal of Zoology, 284, 224-229.

Linkie, M., Martyr, D.J., Holden, J., Yanuar, A., Hartana, A.T., Sugardjito, J. \& Leader-Williams, N. (2003) Habitat destruction and poaching threaten the Sumatran tiger in Kerinci Seblat National Park, Sumatra. Oryx, 37, 41-48.

Linkie, M., Wibisono, H.T., Martyr, D.J. \& Sunarto, S. (2008) Panthera tigris ssp. sumatrae. In The IUCN Red List of Threatened Species, e.T15966A5334836. dx.doi.org/10.2305/IUCN.UK.2008. RLTS.T15966A5334836.en [accessed 13 February 2020].

Meredith, M. \& Ridout, M. (2017) Overview of the overlap package. R Project. cran.radicaldevelop.com/web/packages/overlap/ vignettes/overlap.pdf [accessed 1 April 2018].

Miquelle, D.G., Smirnov, E.N., Merrill, T.W., Myslenkov, A.E., Quigley, H.B., Hornocker, M.G. \& Schleyer, B. (1999) Hierarchical spatial analysis of Amur tiger relationships to habitat and prey. In Riding the Tiger: Tiger Conservation in

Human-Dominated Landscapes (eds J. Seidensticker, S. Christie \& P. Jackson), pp. 71-99. Cambridge University Press, Cambridge, UK.

Ngoprasert, D., Lynam, A.J., Sukmasuang, R., Tantipisanuh, N., Chutipong, W., Steinmetz, R. et al. (2012) Occurrence of three felids across a network of protected areas in Thailand: prey, intraguild, and habitat associations. Biotropica, 44, 810-817.

NowA K, R.M. (1999) Walker's Mammals of the World, 6th edition. John Hopkins University Press, Baltimore, USA.

O'Brien, T.G. \& Kinnaird, M.F. (1996) Birds and mammals of the Bukit Barisan Selatan National Park, Sumatra, Indonesia. Oryx, 30, 207-217.

O’Brien, T.G., Kinnaird, M.F. \& Wibisono, H.T. (2003) Crouching tigers, hidden prey: Sumatran tiger and prey populations in a tropical forest landscape. Animal Conservation, 6, 131-139.

Parsons, A.W., Forrester, T., McShea, W.J., Baker-Whatton, M.C., Millspaugh, J.J. \& Kays, R. (2017) Do occupancy or detection rates from camera traps reflect deer density? Journal of Mammalogy, 98, 1547-1557.

Pusparini, W., Batubara, T., Surahmat, F., Ardiantiono, Sugiharti, T., Muslich, M. et al. (2018) A pathway to recovery: the Critically Endangered Sumatran tiger Panthera tigris sumatrae in an 'in danger' UNESCO world heritage site. Oryx, 52, 25-34.

R Core TeAm (2016) R: a Language and Environment for Statistical Computing. R Foundation for Statistical Computing, Vienna, Austria. R-project.org [accessed 13 February 2020].

Ramakrishnan, U., Coss, R.G. \& Pelkey, N.W. (1999) Tiger decline caused by the reduction of large ungulate prey: evidence from a study of leopard diets in southern India. Biological Conservation, 89, 113-120.

Rich, L.N., Miller, D.A.W., Robinson, H.S., McNutt, J.W. \& Kelly, M.J. (2016) Using camera trapping and hierarchical occupancy modelling to evaluate the spatial ecology of an African mammal community. Journal of Applied Ecology, 53, 1225-1235.

Rich, L.N., Miller, D.A.W., Muñoz, D.J., Robinson, H.S., McNutt, J.W. \& Kelly, M.J. (2019) Sampling design and analytical advances allow for simultaneous density estimation of seven sympatric carnivore species from camera trap data. Biological Conservation, 233, 12-20.

Ridout, M.S. \& Lin Kie, M. (2009) Estimating overlap of daily activity patterns from camera trap data. Journal of Agricultural, Biological, and Environmental Statistics, 14, 322-337.

Rovero, F. \& Zimmermann, F. (2016) Camera Trapping for Wildlife Research, 1st edition. Pelagic Publishing, Exeter, UK.

Saggiomo, L., Picone, F., Esattore, B. \& Sommese, A. (2017) An overview of understudied interaction types amongst large carnivores. Food Webs, 12, 35-39.

Sanderson, E.W., Forrest, J., Loucks, C., Ginsberg, J., Dinerstein, E., Seidensticker, J. et al. (2010) Setting priorities for tiger conservation: 2005-2015. In Tigers of the World, 2nd edition (eds R. Tilson \& P. Nyhusad), pp. 143-161. Academic Press, Cambridge, USA.

Schoener, T.W. (1974) Resource partitioning in ecological communities. Science, 185, 27-39.

Seidensticker, J. (2010) Saving wild tigers: a case study in biodiversity loss and challenges to be met for recovery beyond 2010. Integrative Zoology, 5, 285-299.

Seidensticker, J.C. \& McDougal, C. (1993) Tiger predatory behaviour, ecology and conservation. Symposia of the Zoological Society of London, 65, 105-125.

Sibarani, M.C., Di Marco, M., Rondinini, C. \& Kark, S. (2019) Measuring the surrogacy potential of charismatic megafauna species across taxonomic, phylogenetic and functional diversity on a megadiverse island. Journal of Applied Ecology, 56, 1220-1231.

Song, M.-K., Lin, F.-C., Ward, S.E. \& Fine, J.P. (2013) Composite variables: when and how. Nursing Research, 62, 45-49.

Swanson, A., Kosmala, M., Lintott, C., Simpson, R., Smith, A. \& PACKER, C. (2015) Snapshot Serengeti, high-frequency annotated camera trap images of 40 mammalian species in an African savanna. Scientific Data, 2, 150026.

TEAM Network (2011) Terrestrial Vertebrate Protocol Implementation Manual, version 3.1. Tropical Ecology, Assessment and Monitoring Network, Center for Applied Biodiversity Science, Conservation International, Arlington, USA.

Walston, J., Robinson, J.G., Bennett, E.L., Breitenmoser, U., Da Fonseca, G.A.B., Goodrich, J. et al. (2010) Bringing the tiger back from the brink-the six percent solution. PLOS Biology, $8, \mathrm{e} 1000485$. 